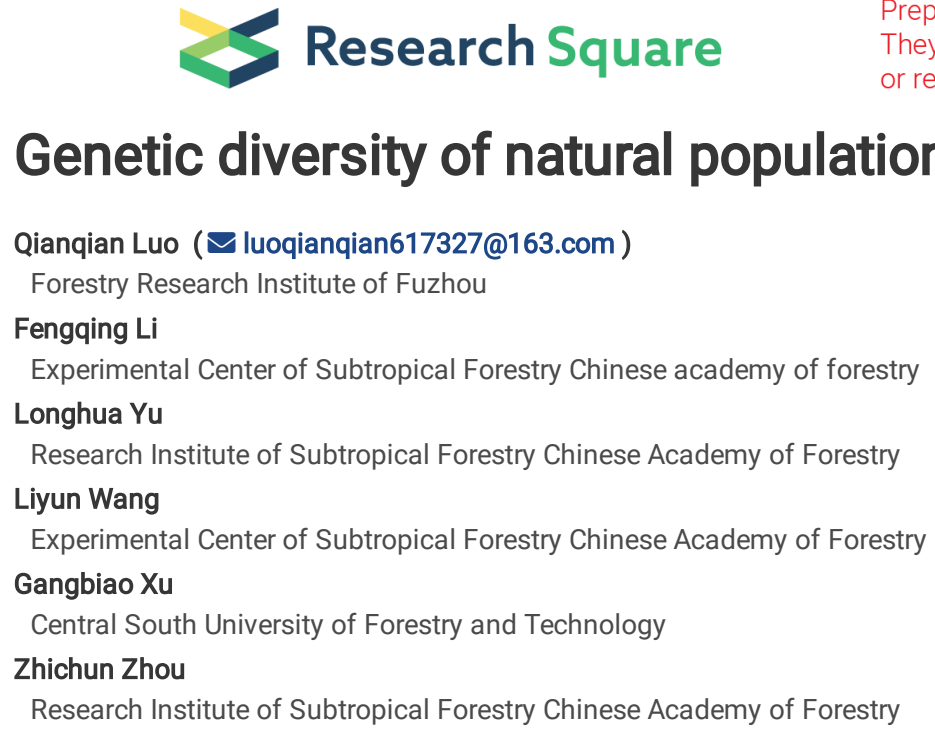

\title{
Genetic diversity of natural populations of Taxus wallichiana var. mairei
}

\section{Research Article}

Keywords: Taxus wallichiana var. mairei, Genetic diversity, Natural populations, SSR

Posted Date: May 7th, 2021

DOI: https://doi.org/10.21203/rs.3.rs-392442/v1

License: (c) (1) This work is licensed under a Creative Commons Attribution 4.0 International License. Read Full License 


\section{Abstract}

Maire yew (Taxus wallichiana var. mairei (Lemée H. Léveillé.) L. K. Fu et Nan Li) is a rare and endangered tree species, and it is also a precious timber species in China. We used 13 microsatellites to assess the genetic diversity and differentiation of 665 Maire yew samples from 18 natural populations. A total of 291 alleles were detected. The average number of alleles $\left(N_{\mathrm{a}}=22.39\right)$, expected heterozygosity $\left(H_{\mathrm{e}}=0.74\right)$, polymorphic information content $(P I C=0.86)$ and Shannon diversity index $(I=1.66)$ of the loci indicated a high level of genetic diversity in natural Maire yew populations. Moreover, gene flow was more active among populations $\left(N_{\mathrm{m}}=1.62\right)$ than within populations. Among the 18 populations, the Xinfeng population in Jiangxi Province has the highest genetic diversity. Although each of the studied populations should be protected from further deforestation and agricultural expansion, the Xinfeng population deserves the highest conservation priority. The results based on analysis of molecular variance showed that genetic variation occurred mainly within populations $(84.90 \% ; P<0.001)$, which indicated that the degree of genetic differentiation of the natural populations of Maire yew was low. Based on UPGMA, the 18 populations were categorized into 4 groups. A Mantel test showed that there was no significant correlation between standard genetic distance and geographical distance or altitude differences among the populations. The genetic clustering results also indicated that the genetic relationship followed a north to south clustered trend. The information presented here forms the basis for the development of genetic guidelines for appropriate conservation programs.

\section{Introduction}

Genetic diversity is the driving force of not only the adaptive evolution and speciation of species but also the ability of species to adapt to a variety of changing environments (diseases, abrupt changes in climate, etc.) (Mullen 2007). Populations with higher genetic diversity are more adaptable in the face of adversity and thus have a greater chance of reproduction and evolution (Mcneely et al. 1990). The genetic diversity of plants is affected by a multitude of factors, including mating system, gene flow, and genetic drift (Wen et al. 2010). Many events in the history of a population will affect the genetic diversity between a population and its distribution, and natural and human interference will also change effective plant population sizes and reduce genetic diversity, further leading to frequent inbreeding. In addition, there is evidence that inbreeding depression is more severe under environmental stress and challenging events (e.g., extreme weather, pollution, or disease) (Mullen 2007). Eventually, the fitness of the individuals in a population will be reduced, so the protection of the genetic diversity of endangered species is necessary (Cheng 2016).

Maire yew is a rare and endangered tree species that is used for medicine, wood and ornamental purposes (Zhou et al. 2009; Vu et al. 2017). Maire yew is mainly distributed in the eastern and southern regions of China, among which there are more natural resources in Zhejiang, Hunan, Jiangxi, Fujian and Guangdong Provinces. The growth of young Maire yew trees requires specific temperature, humidity and light conditions. However, due to the large canopy density in the tree layer and the limited illumination in the forest, Maire yew is prone to aggregation and distribution in a small range. In the natural populations of Maire yew, there were more old trees and fewer young trees, and the number and growth rate of young individuals could not support the expansion of the Maire yew populations ( $\mathrm{Li}$ et al. 2003; Sun et al. 2003). To date, researchers have conducted in-depth studies on the factors endangering Maire yew (Deng et al. 2016), including its physiological and ecological characteristics (Aguilar et al. 2006; Lu et al. 2014), gene flow (Wang et al. 2019), gene cloning (Zhou et al. 2015) and genetic diversity (Cheng 2016; Xie et al. 2017). Through the study of the genetic diversity and genetic structure of Maire yew (Cheng 2016), it was found that the overall genetic diversity of the population was high, but there were some differences at the genetic level. Some populations with low genetic diversity became geographically isolated, patch-like, and small, and reproductive barriers were formed between populations, which blocked gene exchange, aggravated genetic drift and the inbreeding decline of Maire yew populations, and reduced the genetic diversity of natural populations. Moreover, due to its commercial value, a large number of Maire yew have been cut down in recent years, and anthropogenic destruction greatly reduces its population number and size (Cheng 2016; Xie et al. 2017). For the purpose of protecting the wild resources of Maire yew, it is necessary to formulate relatively scientific conservation strategies. A key element of an in situ conservation strategy is the identification of priority conservation units. In general, conservation units are selected for populations with high levels of genetic diversity or with a small and unstable number of individuals within the population (Cheng 2016). Therefore, it is particularly important to study the genetic diversity and genetic structure of Maire yew, determine priority conservation units, and protect and expand its populations.

\section{Materials And Methods}

\section{Population descriptions and sample collection}

From May to July 2018, a total of 665 Maire yew individuals were sampled from 18 populations around mountains in eastern and southern China (Fig. 1; Table 1). Young leaves (needles of the current year's new shoots) were collected, wrapped in tin foil for individual plants, stored in liquid nitrogen for transportation, and then taken back to a laboratory at $-40^{\circ} \mathrm{C}$ for storage. The geographical location of each population was between $109.09^{\circ} \otimes 119.93^{\circ} \mathrm{E}$ and $24.93^{\circ} \otimes 30.12^{\circ} \mathrm{N}$. The zonal vegetation was evergreen and deciduous broad-leaved forest, with an altitude of $300 \otimes 990 \mathrm{~m}$. The soil was mostly red-yellow soil. During sampling, GPS was used to record the longitude, latitude and altitude of the sample plants. The distance between the trees from which samples were collected was not less than $30 \mathrm{~m}$ to prevent proximal relationships between the sample plants. Information on the geographical location of the Maire yew population distribution is shown in. Table 1.

\section{DNA extraction, SSR amplification and genotyping}

A large number of Plant Genomic DNA Rapid Extraction Kits (DN14-CTAB; Aidlab Biotechnologies Co., Ltd, China) was used to extract total genomic DNA. Thirteen primers were selected for amplification based on previously published studies (Table 2; Cheng 2016; Yi et al. 2013). DNA was quantified on a NanoDrop 2000 spectrophotometer (Thermo Fisher Scientific, USA). 
The target sequences were then amplified in $25 \mu \mathrm{L}$ reaction mixtures, which consisted of $12.5 \mu \mathrm{L} 2 \times$ Taq Plus Master Mix (Vazyme Code: p211-02), 8.5 $\mu \mathrm{L}$ $\mathrm{ddH}_{2} \mathrm{O}, 1 \mu \mathrm{L} \mathrm{F} \& \mathrm{R}$ primer $\left(10 \mu \mathrm{mol} \cdot \mathrm{L}^{-1}\right)$, and $2 \mu \mathrm{L}$ template DNA $\left(20 \mathrm{ng} \cdot \mathrm{LL}^{-1}\right)$. The PCR amplification reaction was carried out on a Takara TP600 Thermal Cycler, and the procedure was as follows: initial denaturation at $94^{\circ} \mathrm{C}(5 \mathrm{~min}) ; 35$ cycles of $94^{\circ} \mathrm{C}(30 \mathrm{~s}), 54-63^{\circ} \mathrm{C}(60 \mathrm{~s})$, and $72^{\circ} \mathrm{C}(60 \mathrm{~s})$; and a final extension at $72^{\circ} \mathrm{C}$ (7 min).

Fragments were separated on a Qsep100TM automatic nucleic acid protein analysis system (BiOptic, Taiwan, China) according to the manufacturer's directions and scored in Q-analyze version 3.0 software (BiOptic, Taiwan, China).

\section{Statistical analysis}

Using GenAlEx 6.5 (Peakall and Smouse 2006, 2012), the number of observed alleles $\left(N_{\mathrm{a}}\right)$ and effective alleles $\left(N_{\mathrm{e}}\right)$, observed heterozygosity $\left(H_{\mathrm{o}}\right)$, expected heterozygosity $\left(H_{\mathrm{e}}\right)$, Shannon index (I), fixed index $(F)$, Nei's genetic distance (Nei 1972), genetic identity (Nei 1972), percentage of polymorphic loci $(P P B)$, and number of migrants per generation $\left(N_{\mathrm{m}}\right)$ were calculated based on overall $F_{\mathrm{st}}$. Allele richness $\left(A_{\mathrm{R}}\right)$ and private allelic richness $(P A R)$ were calculated by HPRARE 1.1 (Kalinowski 2004). Micro-Checker 2.2.3 (Oosterhout et al. 2004) was used to calculate null allele frequencies. The polymorphism information content (PIC) of the microsatellite loci was obtained by Cervus software 2.0 (Harlizius et al. 2011 and Kalinowski et al. 2007). Arlequin 3.0 (Excoffier et al. 2005) was used to perform molecular analysis of variance (AMOVA). FSTAT 2.9.3 (Goudet 1995) was used to calculate population inbreeding coefficients $\left(F_{\text {is }}\right)$, gene differentiation coefficients $\left(G_{\mathrm{st}}\right)$ (Nei 1973), genetic variation within populations $\left(H_{\mathrm{s}}\right)$ and total genetic variation $\left(H_{\mathrm{t}}\right)($ Hedrick 2005). Exact HardyWeinberg global tests of heterozygote deficiency were calculated in Genepop on the Web (Raymond and Rousse 1995; Rousset 2008).

The geographical distances between 18 pairs of Maire yew populations were measured by using an electronic map (http://map.baidu.com), and the altitude difference between each pair of populations was calculated by using Excel 2016 software according to the altitude of each population. Then, the geographical distance and altitude difference were converted into the natural logarithm of geographical distance ( $\operatorname{Ln} D)$ and the natural logarithm of altitude difference $(\mathrm{Ln} H)$, respectively. Simple Mantel tests were performed using the genetic distance [Gst/(1- $\left.\left.G_{\mathrm{st}}\right)\right]$ matrix, Ln $D$ matrix and $\mathrm{Ln} H$ matrix in GenAlEx (Holsinger and Weir 2009; Diniz-Filho 2013).

Bootstrapped UPGMA dendrograms were constructed in POPTREE 2 (Takezaki et al. 2010) to visualize Nei's genetic distance (Nei et al. 1983; Takezaki and Nei 2008). Population structure was analyzed using the Bayesian model-based clustering program STRUCTURE 2.3.4 (Hubisz 2009; Pritchard et al. 2000) with the admixture ancestry model. Both allele frequency models (independent and correlated) were run with the length of the burn-in period and MCMC repetitions each set at 100000. Running five repetitions for each potential number of clusters ( $K=1-18$ ), the independent allele model gave highly reproducible estimates of posterior probabilities of the data $[\mathrm{LnP}(D)]$. However, in the correlated allele model, there was significantly greater variability at some $K$ values, requiring an increase in the number of burn-ins and $\mathrm{MCMC}$ repetitions to 200000 . The plateauing nature of the correlated allele $K \mathrm{vs}$. $\mathrm{LnP}(D) \mathrm{graph}$ made inference of the optimal $K$ value difficult, but a $\Delta K$ transformation of the data (Evanno et al. 2005) provided an estimate that was consistent with the independent allele model. The results from STRUCTURE were graphically displayed using DISTRUCT (Rosenberg 2004) and were essentially identical to both models.

\section{Results}

\section{Loci polymorphism}

The genetic diversity of 18 Maire yew populations was examined using 13 nSSR loci (Table 3). A total of 291 alleles were detected in 665 individuals, and the number of alleles varied from 10 to 33 at each locus, with an average of 22.39 . The polymorphic information content $(P I C)$ of each locus was between 0.65 and 0.94 , and the mean value was 0.86 , indicating high polymorphism of the detected loci. The observed $\left(H_{0}\right)$ and expected heterozygosity $\left(H_{\mathrm{e}}\right)$ ranged from 0.03 to 0.94 and from 0.55 to 0.84 , respectively, and the average expected heterozygosity $\left(H_{\mathrm{e}}=0.74\right)$ was higher than the observed heterozygosity $\left(H_{0}=0.56\right)$. The Shannon diversity index ( $/$ ranged from 1.06 to 2.06 , with an average of 1.66 . The inbreeding coefficient $\left(F_{\text {is }}\right)$ ranged from -0.35 to 0.97 , and the mean value was 0.24 , indicating a high degree of heterozygote deletion. The $F_{\text {is }}$ of most loci (except S77, S79, S82 and S93) was more than 0 , indicating that the selected loci were in a heterozygous deletion state. Among the $13 \mathrm{nSSR}$ loci, only 3 loci (S36, S41 and S82) were in Hardy-Weinberg equilibrium, and 3 loci (S24, S34, S44 and S93) deviated from Hardy-Weinberg equilibrium $(P<0.05)$. The other 6 loci significantly deviated from Hardy-Weinberg equilibrium $(P<$ 0.01). Among the 13 loci, 9 contained invalid alleles, and the amplitude of the invalid alleles varied from 0.16 to 0.49 .

\section{Genetic diversity}

The genetic relationships among the Maire yew populations based on nSSR analysis were next examined (Table 4). The overall level of genetic diversity of the Maire yew populations was relatively high. However, different populations had different levels of genetic diversity, with the highest level observed in Maire yew population Jxxf $\left(N_{\mathrm{a}}=11.00, N_{\mathrm{e}}=6.32, H_{0}=0.69, H_{\mathrm{e}}=0.80, l=1.94, A_{\mathrm{R}}=5.42\right.$, and $\left.P A R=0.59\right)$. The lowest value of genetic diversity was observed in the Fjwp population $\left(N_{\mathrm{a}}=6.08, N_{\mathrm{e}}=3.26, H_{\mathrm{o}}=0.37, H_{\mathrm{e}}=0.64, l=1.31, A_{\mathrm{R}}=3.79\right.$, and $\left.P A R=0.18\right)$. The observed heterozygosity $\left(H_{\mathrm{o}}\right)$ of the populations was generally lower than the expected heterozygosity $\left(H_{\mathrm{e}}\right)$. Except for the Hnly population, the fixed index $(F)$ value of the populations was more than 0 , with a mean of 0.25 , and the mean value of the inbreeding coefficient $\left(F_{\text {is }}\right)$ was 0.36 . Both results show that heterozygote deletion exists in the Maire yew populations, which also indicates that inbreeding exists in the populations. The percentage of polymorphic loci $(P P B)$ in all the populations was $100 \%$, indicating a high level of genetic diversity in the Maire yew populations. Sixteen out of 18 populations showed significant deviation from Hardy-Weinberg (heterozygote deficiency) equilibrium over all loci. However, there were a moderate number of Maire yew samples (665) in this study, and the allelic diversity was high, indicating that deviation from Hardy-Weinberg equilibrium did not have a significant impact on the subsequent analysis (Lin 2018). 
At the locus level (Table 5), the $G_{\text {st }}$ (Nei 1973) of the Maire yew populations ranged from 0.06 to 0.33 , with an average value of 0.14 , indicating a low level of genetic differentiation among the populations. The mean values of $H_{\mathrm{t}}$ and $H_{\mathrm{s}}$ were 0.88 and 0.76 , respectively. The $N_{\mathrm{m}}$ across all the loci was estimated to be $1.62\left(F_{\mathrm{st}}\right.$ method), indicating that the overall gene flow was high and that there was adequate gene flow between populations to counter the negative effect of genetic drift on heterozygosity (Nason and Hamrick 1997). Some loci had $N_{\mathrm{m}}$ values less than 1 , indicating relatively little gene flow within populations.

The AMOVA results showed that genetic variation mainly existed within the natural Maire yew populations (84.90\%), and the variation between populations accounted for only $15.10 \%(P<0.001)$, indicating that the variation between populations was smaller than the variation within populations (Table 6$)$.

\section{Population genetic structure}

Nei's genetic distance and the genetic identity among the 18 natural populations showed that the range of genetic distance and genetic consistency between populations were 0.18-1.59 and 0.20-0.83, respectively, which also indicated that there was a certain degree of genetic differentiation among Maire yew populations, which was consistent with the results of the AMOVA analysis. Among the 18 natural populations, the genetic distance was the largest (1.59) and the genetic identity was the smallest $(0.20)$ between Fjwp and Fjfz. The genetic distance was the lowest $(0.18)$ and the genetic identity was the highest $(0.83)$ between Gdlc and Jxwy (Table 7).

The results of the POPTREE genetic clustering analysis showed that the 18 natural populations were divided into 4 categories (Fig. 2). The A group included the Zjla, Zjjs, Hnly, Jxtg and Fjfz populations. The B group included the Zjls, Zjlq, Hnsz, Jxwy, and Gdlc populations. The C group, included the Hnxh, Fjnp, Hngy, Jxxf, Fjmx and Gdlz populations. The D group included the Jxfy and Fjwp populations. Most of the populations in groups A and B were located in the northern part of the distribution of the 18 populations, while the populations in groups $C$ and $D$ were located in the middle and south of the distribution, showing a north-south distribution pattern. Genetic clustering showed that there was no significant correlation in the genetic distance between the populations and their geographical distance. For example, the Zjls and Gdlc populations were geographically remote, but they were categorized into the same group (Group B), indicating that although they were geographically separated, their genetic distance was relatively close.

The results of the Mantel test (Figs. 3 and 4) showed that there was no significant linear correlation between the genetic distance and geographical distance of the Maire yew populations $\left(R^{2}=0.0097, P=0.140\right)$ or altitude difference $\left(R^{2}=0.0253, P=0.110\right)$ between the populations. The natural Maire yew populations are distributed like islands, which may be the reason why there are no obvious geographical patterns among these populations.

After the STRUCTURE results were processed by the Structure Harvester, it was found (Fig. $5 a)$ that the value of $\operatorname{LnP}(D)$ continued to increase, and there was no inflection point. The Delta $K$ value can be used to determine the optimal $K$ value. When $K=4$, Delta $K$ achieves the maximum value (Fig. $5 \mathrm{~b}$ ), indicating that the best number of clusters for the 665 Maire yew individuals is 4 . Based on the assumption that the gene frequencies between populations are not correlated with each other, STRUCTURE software was used to analyze the genetic structure of the 665 Maire yew individuals (Fig. 6 ). According to the optimal $K$ value $(K=4)$, the 665 individuals tested were redivided into 4 groups, and the STRUCTURE results were mostly consistent with the distance tree analysis. There are varying degrees of gene penetration among natural populations of Maire yew. There was relatively more gene penetration among the populations in group $B$, Jxfy in group D, and Hnly in group A. The gene penetration within the Hngy population was significantly lower than that within the group. When $Q \geq 0.6$ for a sample in a certain group, the kinship of the sample is considered relatively low; in contrast, with a lower $Q$ value, the kinship of a sample is considered more complex (Liu et al. 2009). Among the 18 natural populations of Maire yew, most of the populations have 1 to 3 samples with more complex relationships, such as Zjla (3) and Hnsz (3). The total number of samples with complex genetic relationships is 17 , accounting for $2.56 \%$ of the total number of samples, indicating that most of the samples in each population have a single genetic relationship, but a small number of samples contain genetic components of other groups.

\section{Discussion}

Genetic diversity varies greatly among species. Generally, if genetic diversity is higher, then the potential for adaptation to the environment is also greater (Reed and Frankham 2003). Some researchers found that woody plants have a higher genetic diversity than nonwoody plant species with similar life history characteristics. Among woody plants, the genetic diversity of gymnosperms is the highest (Hamrick et al. 1989 and 1996). In this study, the expected heterozygosity of Maire yew ranged from 0.64 (Fjwp) to 0.80 (Jxxf), with an average of 0.74 . Although the Fjfz and Zjls populations were small, their expected heterozygosity was still as high as 0.74 and 0.70 , respectively. Based on studies of the genetic diversity of endangered gymnosperms using SSR markers, the expected heterozygosity of Maire yew was higher than that of Glyptostrobus pensilis $\left(H_{\mathrm{e}}=0.27\right)(\mathrm{Lin} 2018)$, Cathaya argyrophylla $\left(H_{\mathrm{e}}=0.41\right)($ Wang et al. 2010), Metasequoia glyptostroboides $\left(H_{\mathrm{e}}=0.62\right)$ (Chen 2016) and Ginkgo biloba $\left(H_{\mathrm{e}}=0.71\right)$ (Qi et al. 2019); similar to that of $A$ bies chensiensis $\left(H_{\mathrm{e}}=0.73\right)$ and $A$ bies fargesii $\left(H_{\mathrm{e}}=0.74\right)$ (Wang 2014); and significantly higher than the average expected heterozygosity of Taxus $\left(H_{\mathrm{e}}=0.59\right)(C h e n g$ 2016). In general, the genetic diversity of the natural Maire yew populations is high, which indicates that although the natural populations are preserved in fragmented ancient tree stands, they still have high genetic diversity.

The genetic diversity of the Maire yew populations differed, e.g., the genetic diversity of the Jxxf population $\left(N_{\mathrm{e}}=6.14, H_{\mathrm{e}}=0.62\right.$, I= 1.94) was significantly higher than that of the Fjwp population $\left(N_{\mathrm{e}}=3.26, H_{\mathrm{e}}=0.64, I=1.31\right)$. The Jxfy population is experiencing a transformation from cluster type to random type and is large and mostly composed of middle-aged trees. There was a certain proportion of older individuals and females, and the seed setting rate was higher in populations with more female plants. Pollen flows between adjacent individuals under the action of wind, which promotes interindividual outcrossing. In addition, this population is located near human settlements, where local residents will plant Maire yew and exchange its seeds. Long-term popularization and conscious selection may enhance gene flow, inhibit gene drift and increase the genetic diversity of the population. In contrast, in growing populations (Wang 2003), such as the Fjwp population, there are more young individuals and fewer females as well as shorter pollination distances. Moreover, the Fjwp population is located at a higher altitude in the Liangye Mountain Nature Reserve, which is less affected by human interference. Limited gene flow may 
increase inbreeding rates within populations and decrease genetic diversity. For rare and endangered dioecious plants, population size (Cruzan 2001), the degree of human disturbance (Wen et al. 2018), age structure (Zhou et al. 2010), sex ratio and spatial pattern (Song et al. 2020), and other factors affect the success of the species reproduction and the survival potential and natural regeneration ability of the population and influence the maintenance of genetic diversity (Somanothan \& Borges 2000; Iszkulo et al. 2009). In general, the sex ratio of dioecious plants in natural populations is 1:1, but a large number of studies have shown that sex ratio bias is prevalent in dioecious plants (Bertiller et al. 2002; Ortiz et al. 2002; Pucholt et al. 2017). During the sampling process, we also found that in most natural populations of Maire yew, the number of male plants was much greater than that of female plants. The reason for this difference may be related to environmental factors. In general, the number of male plants is much greater than the number of female plants in arid or lownutrient environments, and the number of female plants is much greater in humid or high-nutrient environments (Freeman et al. 1976; Dawson and Ehleringer 1993).

In our work, the analysis of molecular variance showed that genetic variation occurred mainly within populations of Maire yew, which was consistent with the results of previous studies (Zhang et al. 2013). The reason for this result may be that the pollen sources within populations were extensive and there were more flowering and fruiting stock plants. Some researchers have suggested that genetic variation in outbreeding species occurs mostly within populations because pollen from outbreeding plants can be spread far (Wang and Hu 2013). Long-term divergent adaptation to microenvironments may also be a driving force for intrapopulation genetic variation. In addition, genetic variation within a population can be affected by human interference.

Gene flow is an important factor influencing the genetic structure of plant populations, and strong gene flow $\left(N_{\mathrm{m}}>1\right)$ can prevent genetic differentiation caused by genetic drift (Mullen 2007). In this study, the mean value $\left(N_{\mathrm{m}}=1.62\right)$ of gene flow between Maire yew populations was greater than 1 . Human activities have reduced the area and number of natural populations, which has accelerated the process of habitat fragmentation. However, Maire yew seeds can be spread over long distances by animals, promoting gene exchange among natural populations (Li et al. 2014). Moreover, Maire yew is characterized by a short fragmentation time, longevity and wind pollination, so there is no serious genetic differentiation among populations. We should prioritize the protection of populations with high genetic diversity and a high number of private alleles, because genetic variation exists mainly within populations. In situ protection, artificial pollination and transplanting of young seedlings may increase gene flow within populations.

The 18 natural populations of Maire yew could be divided into 4 groups by both distance tree analysis and Bayesian STRUCTURE analysis, and the STRUCTURE results were mostly consistent with the distance tree analysis. In distance tree analysis, the Hnxh and Fjnp populations belong to Group C, but in the Bayesian STRUCTURE analysis, the two populations belong to Group B, because the geographical isolation and the small climate of the populations lead to gene exchange in the populations. There was obvious gene infiltration among most separated groups, and a small number of samples in the population had complex genetic relationships, which indicated that in the process of species evolution, frequent gene exchange and recombination occurred among individuals in the region (Liu et al. 2009), thus resulting in a more abundant genetic structure. The sampling sites selected in this study are mostly located in the southern mountainous areas, with rich species of associated tree species. Although most Maire yew are distributed in patches due to human interference, such patch habitats have attracted a variety of fruit-eating birds. Previous studies have shown that Maire yew could form a reciprocal relationship with fruiteating birds in patch habitats, which significantly affects the seed dispersal pattern and efficiency of Maire yew (Li et al. 2014). Based on genetic structure, the Fjwp and Jxfy populations were divided into the same group (group D). However, the degree of gene penetration in the Fjwp population was significantly higher than that in the Jxfy population, which may be related to the influence of habitat. The Fjwp population is located at an altitude of $800-1050 \mathrm{~m}$ in the Liangye Mountain Nature Reserve, Fujian Province. The nature reserve is rich in wildlife, and Maire yew are found along the southern stream, near highhumidity areas, such as fast flowing water, expanding the scope of seed propagation. This also shows that water plays a key role in gene flow and ontogeny.

An increased understanding of genetic diversity among and within natural populations can contribute to the conservation of protected areas and regional development. Our results show that the species studied herein has a high genetic diversity in the the eastern and southern regions of China. As with most subtropical, outcrossing, wind pollinated species, and similar to most of the arboreal forest taxa in the Northern Hemisphere, the majority of the species diversity is concentrated within populations. Through the study of the genetic diversity and genetic structure of Maire yew, it was found that the overall genetic diversity of the population was high, but there were some differences at the genetic level, which indicated that the genetic evolution potential of Maire yew was great. Based on the research results of this project, the Xinfeng natural populations with the highest genetic diversity, have a large number of the individuals and relatively concentrated individual distribution, and should be given priority for protection. At the same time, special attention should be paid to the protection of Maire yew populations growing near natural villages to avoid the loss of genetic diversity caused by human destruction or natural disasters. It is recommended to carry out research on the mating system of Maire yew, in order to obtain more reliable information on the genetic diversity and endangerment of Maire yew population, and to provide a scientific and comprehensive theoretical basis for the protection strategy of Maire yew genetic resources.

\section{Declarations}

\section{Acknowledgements}

The authors are grateful to all the workers who participated in the sample collection in Research Institute of Taxus Industry in Fujian Province and Forestry Academy in Longquan City of Zhejiang Province. This research was funded by fundamental Research Funds of the Central Public Welfare Research Institutes, Chinese Academy of Forestry (No.CAFYBB2018ZB010).

\section{Competing interests}

The authors declare that they have no competing interests.

\section{Funding info}


This research was funded by fundamental Research Funds of the Central Public Welfare Research Institutes, Chinese Academy of Forestry (No.CAFYBB2018ZB010).

\section{Authors' contributions}

Qianqian Luo conceived the study. Samples were collected by Longhua Yu, Liyun Wang, and Qianqian Luo. DNA isolation, PCR, and genotyping were conducted by Qianqian Luo. Data were analyzed by Qianqian Luo, Fengqing Li and Gangbiao Xu. The manuscript was written by Qianqian Luo, Zhichun Zhou, Fengqing Li, and Gangbiao Xu. All authors have reviewed the final version of the manuscript.

\section{Data availability}

The microsatellite dataset from the current study is available from the corresponding author upon request. Nuclear microsatellite loci sequences is provided in Table 2 .

\section{Animal research (Ethics)}

No animal or human trials were involved in this study.

\section{Consent to participate (Ethics)}

Not applicable.

\section{Consent to publish (Ethics)}

Not applicable.

\section{References}

Aguilar R, Ashworth L, Galetto L, Aizen MA (2006) Plant reproductive susceptibility to habitat fragmentation: review and synthesis through a meta-analysis. Ecology Letters 9: 968-980. doi:10.1111/j.1461-0248.2006.00927.x

Bertiller MB, Sain CL, Carrera AL (2002) Effect of fine-scale spatial variation of soil nitrogen on the performance of the sexes of Poa ligularis in patchy ecosystems of Northern Patagonia. International Journal of Plant Sciences 163:419-425. doi:10.1086/339515

Chen WW (2016) Mating system and dispersal patterns of the natural populations of Metasequoia glyptostroboides. East China Narmal University (in Chinese)

Cheng B B (2016) Molecular phylogeographic and genetic of Taxus L.(Taxaceae) in China. Chinese Academy of Forestry pp;78 (in Chinese)

Cruzan MB (2001) Population size and fragmentation thresholds for the maintenance of genetic diversity in the herbaceous endemic scutellaria montana (lamiaceae). Evolution 55(8):1569-1580. doi:10.1111/j.0014-3820.2001.tb00676.x

Dawson TE, Ehleringer JR (1993) Gender-specific physiology, carbon isotope discrimination, and habitat distribution in boxelder, Acer negundo. Ecology 74(3):798-815. doi:10.2307/1940807

Deng YT, Liu XS, Xiao YF, Guo XD, Zhang D, Xu GB (2016) The Endangered Causes and Conversation for Chinese Yew. Guangxi Forestry Science 45(4): 442446. doi:10.19692/j.cnki.gfs.2016.04.019 (in Chinese)

Diniz-Filho JAF, Soares TN, Lima JS, Dobrovolski R, Landeiro VL, Telles MPdC, Rangel TF, Bini LM (2013) Mantel test in population genetics. Genetics and Molecular Biology 36(4):475-485. doi:10.1590/S1415-47572013000400002

Dubreuil M, Riba M, Gonzalez-Martinez S C, Vendramin GG, Sebastiani F, Mayol M (2010) Genetic effects of chronic habitat fragmentation revisited: strong genetic structure in a temperate tree, Taxus baccata (Taxaceae), with great dispersal capabilit. American Journal of Botany 97(2): 303-310. doi:10.3732/ajb.0900148

Evanno G, Regnaut S, Goudet J (2005) Detecting the number of clusters of individuals using the software STRUCTURE: a simulation study. Mol Ecol 14: 26112620. doi: 10.1111/j.1365-294X.2005.02553.x

Excoffier L, Laval G, Schneider S (2005) Arlequin (version 3.3): an integrated software package for population genetic data analysis. Evolutionary Bioinformatics Online 1: 47-50

Fan L, Wang YQ, Wang QY (2012) Advances in research ontaxol production by cell culture in Taxus chinensis var. Mairei. Nonwood Forest Research 30(2):134139.

Freeman DC, Klikoff LG, Harper KT (1976) Differential resource utilization by the sexes of dioecious plants. Science 193:597-599. doi:10.1126/science.193.4253.597 
Goudet J (1995) FSTAT (Version-1.2): a computer program to calculate F-statistics. Journal of Heredity, 86(6): 485-486.

doi:10.1093/oxfordjournals.jhered.a111627.

Hamrick JL, Godt NJW (1989) Allozyme diversity in plant species. Plant Population Genetic, Breeding \& Genetic Resources pp $43-63$.

Hamrick JL, Godt NJW (1996) Effects of life history traits on genetic diversity in plant species. Philosophical Transactions of the Royal Society B Biological Sciences 351: 1291-1298. doi:10.1098/rstb.1996.0112

Harlizius B, Lopes MS, Duijvesteijn N, Goor LHPVD, Haeringen WAV, Pannenian H, Guiniaräes SEF, Merks JWM, Knol EF (2011). A single nucleotide polymorphism set for paternal identification to reduce the costs of trait recording in commercial pig breeding. Journal of Animal Science 89:1661-1668. doi:10.2527/jas.2010-3347

Hedrick PW (2005) A Standardized Genetic Differentiation Measure. Evolution 59(8):1633-1638. doi:10.2307/3449070

Holsinger KE, Weir BS (2009) Genetics in geographically structured populations: defining, estimating and interpreting $F_{\text {ST. Nature Reviews Genetics } 10: 639-650 .}$ doi: $10.1038 / \mathrm{nrg} 2611$

Hubisz MJ, Falush D, Stephens M, Pritchard J K (2009) Inferring weak population structure with the assistance of sample group information. Molecular Ecology Resources 9(5):1322-1332. doi:10.1111/j.1755-0998.2009.02591.x.

Iszkuło G, Jasińska AK, Giertych MJ, Boratyński A (2009) Do secondary sexual dimorphism and female intolerance to drought influence the sex ratio and extinction risk of Taxus baccata? Plant Ecology 200:229-240. doi:10.1007/s11258-008-9447-5

Kalinowski ST(2004) HP-RARE 1.0: a computer program for performing rarefaction on measures of allelic richness. Molecular Ecology Notes 5(1): 187-189. doi:10.1111/j.1471-8286.2004.00845.x

Kalinowski ST, Taper M L, Marshall TC (2007) Revising how the computer program CERVUS accommodates genotyping error increases success in paternity assignment. Molecular ecology 16:1099-1106. doi:10.1111/j.1365-294x.2007.03089.x

Kim J, Rohlf J, Sokal RR (1993) The accuracy of phylogenetic estimation using the neighbor-joining method. Evolution 47(2): 471-486. doi:10.2307/2410065.

Li N, Wang Z, Lu CH, Xiong TS, Fu WY, Wu JP (2014) Seed foraging and dispersal of Chinese yew (Taxus chinensis var. mairei) by frugivorous birds within patchy habitats. Acta Ecologica Sinica 34(7): 1681-1689. doi:10.5846/xtxb201303220485 (in Chinese)

Li XK, Xiang WS, Ou ZL, Su ZM (2003) Clonal growth Spatial attern and dynamics of the endangered Plant Taxus mairei population. Acta Botanica Yunnanica 25(6):625-632 (in Chinese)

Lin XY (2018) Development of EST-SSR markers and population genetic variation in Glyptostrobus pensilis. Central South University of Forestry\&Technology (in Chinese)

Liu LH, Wang LX, Zhao CP, Yao J, Zhang FT, Zhang H, Ye ZJ, Qin ZL, Zheng YL (2009) Genetic diversity and alterations of population structure in restorers of dual cross-line hybrid wheat with thermo-photoperiod sensitive male sterile. Chinese Journal of Biochemistry and Molecular Biology25(9): 867-875. doi:10.13865/j.cnki.cjbmb.2009.09.013 (in Chinese)

Lu DW, Zhou YQ, Li SB, Yu XS Li SH, Zhang CH, Yang C, Yang S, Yang ZY (2014) Biological characteristics, ecological characteristics and cultivation techniques in Taxus chinensis var. mairei. Non wood forest research 32(4): 159-164 (in Chinese)

Mcneely JA, Miller KR, Reid WV, et al. Conserving the world's biological diversity. Conserving the world's biological diversity. Prepared and published by the International Union for Conservation of Nature and Natural Resources, 1990.

Mullen SP (2007) Conservation and the Genetics of Populations. Blackwell, London

Nei M (1972) Genetic Distance between Populations. The American Naturalist, 106(949):283-292. doi:10.1086/282771

Nei M (1973) Analysis of gene diversity in subdivided populations. Proceedings of the National Academy of ences 70(12):3321-3323. doi:10.2307/62835

Nei M, Tajima F, Tateno Y (1983) Accuracy of estimated phylogenetic trees from molecular data. II. Gene frequency data. J Mol Evol 19:153-170. doi:10.1007/bf02300753

Oosterhout CV, Hutchinson WF, Wills DPM, Shipley P (2004) micro-checker: software for identifying and correcting genotyping errors in microsatellite data. Molecular Ecoiogy Notes 4: 535-538. doi:10.1111/j.1471-8286.2004.00684.x

Ortiz P L, Arista M, Talavera S (2002) Sex ratio and reproductive effort in the dioecious Juniperus communis subsp. Alpina (Suter) Čelak. (Cupressaceae) along an altitudinal gradient. Annals of Botany 89:205-211. doi:10.1093/aob/mcf028

Peakall R, Smouse PE (2006) GENALEX 6: Genetic analysis in Excel. Population genetic software for teaching and research. Mol Ecol Notes 6:288-295. doi: 10.1111/j.1471-8286.2005.01155.x 
Peakall R, Smouse PE (2012) GenAlEx 6.5: genetic analysis in Excel. Population genetic software for teaching and research-an update. Bioinformatics 28:2537-2539. doi:10.1093/bioinformatics/bts460

Pritchard JK, Stephens M, Donnelly P (2000) Inference of population structure using multilocus genotype data.Genetics 155(2):945-959

<https://wenku.baidu.com/view/a780993bfd0a79563c1e72c6.html>

Pucholt P, Hallingbäck HR, Berlin S (2017) Allelic incompatibility can explain female biased sex ratios in dioecious plants. BMC Genomics 18:251.

doi:10.1186/s12864-017-3634-5

Qi M, Zhou Q, Ni ZX, Wu YQ, Han X, Xu LA (2019) Genetic structure analysis of ancient Ginkgo biloba L. populations based on SSR markers. Chinese journal of ecology 38(9):2902-2910. doi:10.13292/j.1000-4890.201909.017. (in Chinese)

Raymond M, Rousset F (1995) GENEPOP (Version 1.2): Population genetics software for Exact tests and ecumenicism. Journal of Heredity 86(3):248-249. doi:10.1093/oxfordjournals.jhered.a111573

Reed DH, Frankham R (2003) Correlation between Fitness and Genetic Diversity. Conservation Biology 17(1):230-237. doi:10.1046/j.1523-1739.2003.01236.x

Rosenberg NA (2004) DISTRUCT: a program for the graphical display of population structure. Mol Ecol Notes 4:137-138. doi:10.1046/j.1471-

8286.2003.00566.x

Rousset F (2008) genepop'007: a complete re-implementation of the genepop software for Windows and Linux. Molecular Ecology Resources 8:103-106. doi:10.1111/j.1471-8286.2007.01931.x

Somanothan H, Borges RM (2000) Influence of exploitation on population structure, spatial distribution and reproductive success of dioecious species in a fragmented cloud forest in India. Biological Conservation, 94:243-256. doi:10.1016/s0006-3207(99)00170-6

Song YB, Xu L, Duan JP, Zhang WJ, Shentu XL, Li TX, Zang RG, Ming Dong M (2020) Sex ratio and spatial pattern of Taxus fuana, a wild plant with extremely small populations in Tibet. Biodiversity Science 28(3):269-276. doi: 10.17520/biods.2019102 (in Chinese)

Sun QW,Wang L, Zhang XP, Hao CY, Tian SN (2009) Study on the Population Dynamics of Taxus chinensis var. mairei in the Mountain Area of Southern Anhui Province. forest research 22(4): 579-585 (in Chinese)

Takezaki N, Nei M (2008) Empirical tests of the reliability of phylogenetic trees constructed with microsatellite DNA. Genetics 178:385-392. doi:10.1534/genetics.107.081505

Takezaki N, Nei M, Tamura K (2010) POPTREE 2: Software for constructing population trees from allele frequency data and computing other population statistics with Windows interface. Mol Biol Evol 27:747-752. doi:10.1093/molbev/msp312

Tsumura Y, Kawahara T, Wickneswari R, Yoshimura K (1996) Molecular phylogeny of Dipterocarpaceae in Southeast Asia using RFLP of PCR-amplified chloroplast genes. Theoretical \& Applied Genetics 93: 22-29. doi:10.1007/BF00225722.

Vu DD, Bui TTX, Nguyen MT, Vu DG, Nguyen MD, Bui VT, Huang XH, Zhang Y(2014) Genetic diversity in two threatened species in Vietnam: Taxus chinensis and Taxus wallichiana. Journal of Forestry Research 28: 265-272. doi: 10.1007/s11676-016-0323-1

Wang HX, Hu ZA (1996) Plant breeding system, genetic structure and conservation of genetic diversity. Chinese Biodiversity 4( 2):92-96

Wang MQ, Wu XT, Wang LB, Wen YF (2019) Comparison of Gene flow for Taxus chinensis var. mairei. Molecular Plant Breeding 17(19): 6269-6275. doi: 10.13271/j.mpb.017.006269 (in Chinese)

Wang XG (2003) The research on population quantiative characteristics of precious and endangering plant-Form Taxus chinensis var. mairei. Graduate Thesis of Fujian Agriculture\&Forestry University. (in Chinese)

Wang X (2014) Comparative analysis of population genetic structure in Abies chensiensis and A.fargesii inferred from microsatellite markers. Guangxi Normal University. (in Chinese)

Wang ZS, Sun HQ, Wang HW, Ge S. (2010) Isolation and characterization of 50 nuclear microsatellite markers for Cathaya argyrophylla, a Chinese endemic conifer. American Journal of Botany 97(11): e117-e120. doi:10.3732/ajb.1000270

Wen YF, HanWJ, Wu S (2010) Plant genetic diversity and its influencing factors. J. Cent. South Univ. For. Technol 32(7):1-7. (in Chinese)

Xie WD (2017) Research on the correlation of genetics of Taxus chinensis var. Mairei in Nanling Mountain. Central south universityof forestry and technology. pp: 76-77.(in Chinese)

Yi GM, Li JH, Wang DM, Tong ZK, Lu YQ (2013) SSR Distribution characteristic analysis and molecular marker development in Taxus wallichiana var. Mairei. Acta Horticulturae Sinica 40(3): 571-578. doi:10.16420/j.issn.0513-353x.2013.03.031 (in Chinese)

Zhang DQ, Zhou N (2013) Genetic diversity and population structure of the endangered conifer Taxus wallichiana var. mairei (Taxaceae) revealed by Simple Sequence Repeat (SSR) markers. Biochemical Systematics \& Ecology 49: 107-114. doi:10.1016/j.bse.2013.03.030

Page $8 / 17$ 
Zhou H, Zhu Q, Yang YF, Liu HW, Yu FX, Qiu DY (2015) Cloning and sequence analysis of bHLHgene from Taxus chinensis var. mairei. Bulletin of Botanical Research 35(1):52-59 (in Chinese)

Zhou SR, Zhou CC, Pannell JR (2010) Genetic load, inbreeding depression and heterosis in an age-structured metapopulation 23(11):2324-2332. doi:10.1111/j.1420-9101.2010.02091.x

\section{Tables}

\section{Table 1}

The studied populations

\begin{tabular}{|lllllll|}
\hline No. & Population code & Location & N & Latitude $\left({ }^{\circ} \mathrm{N}\right)$ & Longititude $\left({ }^{\circ} \mathrm{E}\right)$ & Altitude(m凶 \\
\hline 1 & Zjla & Linan, Zhejiang & 26 & 30.02 & 119.04 & 629 \\
\hline 2 & Zjls & Lishui, Zhejiang & 19 & 28.52 & 119.93 & 791 \\
\hline 3 & Zjjs & Jiangshan, Zhejiang & 22 & 28.30 & 118.55 & 713 \\
\hline 4 & Zjlq & Longquan, Zhejiang & 22 & 28.01 & 118.80 & 629 \\
\hline 5 & Hnsz & Sangzhi, Hunan & 47 & 29.73 & 109.80 & 640 \\
\hline 6 & Hnly & Liuyang, Hunan & 51 & 28.37 & 114.17 & 300 \\
\hline 7 & Hnxh & Xinhuang, Hunan & 47 & 27.29 & 109.09 & 683 \\
\hline 8 & Hngy & Guiyang, Hunan & 51 & 25.55 & 112.66 & 610 \\
\hline 9 & Jxwy & Wuyuan, Jiangxi & 32 & 29.40 & 117.61 & 350 \\
\hline 10 & Jxtg & Tonggu, Jiangxi & 51 & 28.68 & 114.15 & 475 \\
\hline 11 & Jxfy & Fenyi, Jiangxi & 49 & 27.62 & 114.54 & 626 \\
\hline 12 & Jxxf & xinfeng, Jiangxi & 50 & 25.42 & 114.93 & 530 \\
\hline 13 & Fjnp & Nanping, Fujian & 35 & 26.69 & 118.07 & 790 \\
\hline 14 & Fjmx & Mingxi, Fujian & 37 & 26.49 & 116.87 & 704 \\
\hline 15 & Fjfz & Fuzhou, Fujian & 14 & 25.97 & 119.11 & 708 \\
\hline 16 & Fjwp & Wuping, Fujian & 23 & 25.19 & 116.18 & 990 \\
\hline 17 & Gdlc & Lechang, Guangdong & 49 & 25.11 & 113.22 & 658 \\
\hline 18 & Gdlz & Lianzhou, Guangdong & 40 & 24.93 & 112.72 & 607 \\
\hline & & & & \\
\hline
\end{tabular}

$N$ the number of individuals analyzed.

\section{Table 2}

Characteristics of thirteen SSR loci. 


\begin{tabular}{|c|c|c|c|c|}
\hline Locus & Primer sequence $\left(5^{\prime}-3^{\prime}\right)$ & Length(bp) & Annealing temperature $\left({ }^{\circ} \mathrm{C}\right)$ & Reference \\
\hline \multirow[t]{2}{*}{ S7 } & F:ACCCCATAGTTCAGGGTCGA & $149-292$ & 57 & Cheng (2016) \\
\hline & R:AGAAGGAGGCTCGGCTCTAA & & & \\
\hline \multirow[t]{2}{*}{ S24 } & F:TGCTTAGAGAAGAAAGTTTTCCA & $145-312$ & 54 & Yi et al. (2013) \\
\hline & R:TGGCATACAAGAGGCTGACA & & & \\
\hline \multirow[t]{2}{*}{ S34 } & F:ATAACCATCACACGTGACTTGC & 193-300 & 57 & Yi et al. (2013) \\
\hline & R:TGAACCCTAGGTGACGACCAT & & & \\
\hline \multirow[t]{2}{*}{ S36 } & F:TGGTTTACATATTGAAGCGAGCAA & 109-176 & 55 & Yi et al. (2013) \\
\hline & R:GCAGCGAAACATATGTAGCACAA & & & \\
\hline \multirow[t]{2}{*}{ S41 } & F:GGACAAGGGTTGGATCACTTCTGT & $203-294$ & 61 & Yi et al. (2013) \\
\hline & R:CCAACGGCCACCCGAAGAGT & & & \\
\hline \multirow[t]{2}{*}{ S44 } & F:TGACAACACAACCACACAATGTCCA & $133-375$ & 57 & Yi et al. (2013) \\
\hline & R:TCTTGTTTTCTGGGCCTAAAGTGT & & & \\
\hline \multirow[t]{2}{*}{ S45 } & F:GCGCTAGTCCTCAGTGGTGCC & $134-272$ & 63 & Yi et al. (2013) \\
\hline & R:GCGCCGGGGCCAACTAAACT & & & \\
\hline \multirow[t]{2}{*}{ S64 } & F:GCATTCTGCTCCTGAGTGTGGCA & 223-397 & 61 & Yi et al. (2013) \\
\hline & R:AGTAGTCTATCCTCGTCTCCTCCCA & & & \\
\hline \multirow[t]{2}{*}{ S70 } & F:AGTAGTCTATCCTCGTCTCCTCCCA & $188-475$ & 61 & Yi et al. (2013) \\
\hline & R:GGGCCTGTGATGCATCTGTCCA & & & \\
\hline \multirow[t]{2}{*}{ S77 } & F:CCAATGTGGGCTACATCCACC & $178-357$ & 58 & Yi et al. (2013) \\
\hline & R:ATTGTAATAGCATGGATAAGTGCCC & & & \\
\hline \multirow[t]{2}{*}{ S79 } & F:AGTTTGCATGCTCTTCAACCTAGT & $176-249$ & 57 & Yi et al. (2013) \\
\hline & R:AGGCAGAATCGGTGAGTGGTT & & & \\
\hline \multirow[t]{2}{*}{ S82 } & F:TGTCGCATCGAGGACGATGCTTTC & $201-434$ & 62 & Yi et al. (2013) \\
\hline & R:CATGGCGGCGGCAGTTCTTG & & & \\
\hline \multirow[t]{2}{*}{ S93 } & F:CAGGGCTCAAATTCGCGGGC & $147-195$ & 62 & Yi et al. (2013) \\
\hline & R:CCGCCTGGCGTTTGACAGGA & & & \\
\hline
\end{tabular}

\section{Table 3}

Statistics of genetic diversity of different SSR microsatellite loci 


\begin{tabular}{|lllllllllll|}
\hline Locus & $N_{\mathrm{a}}$ & $N_{\mathrm{e}}$ & $H_{\mathrm{o}}$ & $H_{\mathrm{e}}$ & $P I C$ & $I$ & $F_{\text {is }}$ & $F$ & HW & Null \\
S7 & 25 & 6.22 & 0.41 & 0.81 & 0.93 & 1.98 & 0.49 & 0.49 & $* *$ & $\mathrm{Y}(0.28)$ \\
\hline $\mathrm{S} 24$ & 22 & 6.44 & 0.64 & 0.82 & 0.88 & 2.03 & 0.23 & 0.23 & $*$ & $\mathrm{Y}(0.16)$ \\
S34 & 22 & 5.90 & 0.60 & 0.80 & 0.89 & 1.95 & 0.26 & 0.25 & $*$ & $\mathrm{Y}(0.18)$ \\
\hline S36 & 12 & 2.38 & 0.32 & 0.56 & 0.65 & 1.06 & 0.43 & 0.41 & $\mathrm{~ns}$ & $\mathrm{Y}(0.24)$ \\
\hline S41 & 18 & 2.63 & 0.47 & 0.55 & 0.84 & 1.07 & 0.16 & 0.26 & $\mathrm{~ns}$ & $\mathrm{Y}(0.22)$ \\
\hline S44 & 29 & 5.52 & 0.66 & 0.81 & 0.90 & 1.90 & 0.18 & 0.17 & $*$ & $\mathrm{Y}(0.16)$ \\
\hline S45 & 27 & 6.68 & 0.37 & 0.84 & 0.90 & 2.06 & 0.55 & 0.56 & $* * *$ & $\mathrm{Y}(0.29)$ \\
\hline S64 & 30 & 6.18 & 0.03 & 0.81 & 0.94 & 1.97 & 0.97 & 0.96 & $* *$ & $\mathrm{Y}(0.49)$ \\
\hline S70 & 33 & 4.82 & 0.28 & 0.72 & 0.92 & 1.60 & 0.62 & 0.64 & $* * *$ & $\mathrm{Y}(0.35)$ \\
\hline S77 & 25 & 4.19 & 0.88 & 0.72 & 0.87 & 1.51 & -0.21 & -0.22 & $* *$ & $\mathrm{~N}$ \\
\hline S79 & 16 & 3.65 & 0.94 & 0.70 & 0.83 & 1.36 & -0.35 & -0.38 & $* * *$ & $\mathrm{~N}$ \\
\hline S82 & 22 & 4.16 & 0.82 & 0.75 & 0.84 & 1.61 & -0.10 & -0.10 & $\mathrm{~ns}$ & $\mathrm{~N}$ \\
\hline S93 & 10 & 3.94 & 0.84 & 0.73 & 0.85 & 1.52 & -0.15 & -0.16 & $*$ & $\mathrm{~N}$ \\
\hline Overall & 22.39 & 4.82 & 0.56 & 0.74 & 0.86 & 1.66 & 0.24 & 0.24 & $*$ & \\
\hline
\end{tabular}

$N_{\mathrm{a}}$ number of alleles, $N_{\mathrm{e}}$ number of effective alleles, $H_{\mathrm{o}}$ observed heterozygosity, $H_{\mathrm{e}}$ expected heterozygosity, PIC polymorphism information content, $I$ Shannon's diversity index, $F_{\text {is }}$ inbreeding coefficient, $F$ fix index, $H W$ exact test of heterozygosity deficiency, Null estimate of null allele frequency, $n s$ not significant

Overall values are averages for $N_{\mathrm{a}}, N_{\mathrm{e}}, H_{0}, H_{\mathrm{e}}, P I C, I, F_{\mathrm{is},} F$ and null; global for $F_{\text {is. }}{ }^{\star} P<0.05, * \star P<0.01, * \star \star P<0.001$, the same below

\section{Table 4}

Statistics of genetic diversity in populations of Maire yew

\begin{tabular}{|llllllllllll|}
\hline Population & $\mathrm{Na}$ & $\mathrm{Ne}$ & $\mathrm{Ho}$ & $\mathrm{He}$ & $\mathrm{I}$ & $F$ & $F_{\text {is }}$ & $A_{\mathrm{R}}$ & $P A R$ & $\mathrm{HW}$ & $P P B / \%$ \\
\hline Zjla & 8.15 & 5.25 & 0.58 & 0.79 & 1.76 & 0.27 & 0.29 & 5.05 & 0.19 & $*$ & 100 \\
\hline Zjla & 8.15 & 5.25 & 0.58 & 0.79 & 1.76 & 0.27 & 0.29 & 5.05 & 0.19 & $*$ & 100 \\
\hline Zjls & 5.69 & 3.72 & 0.55 & 0.70 & 1.42 & 0.19 & 0.24 & 4.08 & 0.10 & $* * *$ & 100 \\
\hline Zjjs & 7.08 & 4.05 & 0.65 & 0.70 & 1.50 & 0.05 & 0.10 & 4.33 & 0.15 & $*$ & 100 \\
\hline Zjlq & 7.46 & 4.88 & 0.67 & 0.75 & 1.64 & 0.08 & 0.14 & 4.71 & 0.37 & ns & 100 \\
\hline Hnsz & 10.39 & 6.10 & 0.55 & 0.79 & 1.87 & 0.29 & 0.31 & 5.20 & 0.32 & $* *$ & 100 \\
\hline Hnly & 8.85 & 3.97 & 0.69 & 0.71 & 1.55 & 0.00 & 0.04 & 4.27 & 0.13 & $* *$ & 100 \\
\hline Hnxh & 9.46 & 5.30 & 0.49 & 0.75 & 1.76 & 0.38 & 0.36 & 4.96 & 0.27 & $*$ & 100 \\
\hline Hngy & 9.77 & 5.57 & 0.60 & 0.79 & 1.82 & 0.23 & 0.25 & 5.04 & 0.27 & $* *$ & 100 \\
\hline Jxwy & 8.46 & 4.61 & 0.57 & 0.72 & 1.65 & 0.20 & 0.22 & 4.70 & 0.17 & $*$ & 100 \\
\hline Jxtg & 9.08 & 4.31 & 0.49 & 0.76 & 1.68 & 0.35 & 0.37 & 4.58 & 0.27 & $* * *$ & 100 \\
\hline Jxfy & 6.69 & 3.39 & 0.52 & 0.65 & 1.33 & 0.22 & 0.20 & 3.77 & 0.12 & $* *$ & 100 \\
\hline Jxxf & 11.00 & 6.32 & 0.69 & 0.80 & 1.94 & 0.12 & 0.15 & 5.42 & 0.59 & $* *$ & 100 \\
\hline Fjnp & 9.85 & 5.60 & 0.52 & 0.76 & 1.82 & 0.36 & 0.34 & 5.17 & 0.24 & $* *$ & 100 \\
\hline Fjmx & 9.15 & 5.72 & 0.68 & 0.79 & 1.80 & 0.12 & 0.14 & 5.06 & 0.30 & $* * *$ & 100 \\
\hline Fjfz & 6.54 & 4.23 & 0.43 & 0.74 & 1.57 & 0.42 & 0.44 & 4.64 & 0.06 & ns & 100 \\
\hline Fjwp & 6.08 & 3.26 & 0.37 & 0.64 & 1.31 & 0.46 & 0.48 & 3.79 & 0.18 & $*$ & 100 \\
\hline Gdlc & 9.77 & 5.07 & 0.46 & 0.75 & 1.76 & 0.35 & 0.40 & 4.89 & 0.22 & $*$ & 100 \\
\hline Gdlz & 10.54 & 5.49 & 0.53 & 0.72 & 1.75 & 0.27 & 0.28 & 4.93 & 0.60 & $*$ & 100 \\
\hline Overall & 8.56 & 4.82 & 0.56 & 0.74 & 1.66 & 0.24 & 0.36 & 4.70 & 0.25 & $*$ & 100 \\
\hline
\end{tabular}


$A_{\mathrm{R}}$ allele richness, $P A$ private allelic richness, $P P B$ Percentage of polymorphic sites, Overall values are averages for $A_{\mathrm{R}}, P A R$ and $P P B$

\section{Table 5}

Genetic differentiation parameters of different loci

\begin{tabular}{|lllll|}
\hline Locus & $G_{\mathrm{st}}$ & $H_{\mathrm{s}}$ & $H_{\mathrm{t}}$ & $N_{\mathrm{m}}$ \\
\hline S7 & 0.11 & 0.83 & 0.93 & 1.71 \\
\hline S24 & 0.06 & 0.84 & 0.89 & 2.99 \\
S34 & 0.09 & 0.82 & 0.9 & 2.19 \\
\hline S36 & 0.19 & 0.57 & 0.71 & 0.95 \\
\hline S41 & 0.33 & 0.57 & 0.85 & 0.47 \\
S44 & 0.09 & 0.82 & 0.9 & 2.11 \\
\hline S45 & 0.06 & 0.86 & 0.91 & 2.82 \\
\hline S64 & 0.11 & 0.84 & 0.95 & 1.49 \\
\hline S70 & 0.19 & 0.75 & 0.92 & 0.9 \\
\hline S77 & 0.16 & 0.74 & 0.87 & 1.23 \\
\hline S79 & 0.17 & 0.71 & 0.85 & 1.15 \\
\hline S82 & 0.12 & 0.76 & 0.86 & 1.64 \\
\hline S93 & 0.14 & 0.74 & 0.86 & 1.37 \\
\hline Mean & 0.14 & 0.76 & 0.88 & 1.62 \\
\hline
\end{tabular}

$G_{\mathrm{st}}$ gene differentiation coefficient, $H_{\mathrm{s}}$ gene diversity within population, $H_{\mathrm{t}}$ total gene diversity, $N_{\mathrm{m}}$ number of migrants per generation

\section{Table 6}

Analysis of molecular variance (AMOVA) for populations of Maire yew based on SSR markers

\begin{tabular}{|lllllll|}
\hline Source of variation & $d f$ & SSD & Variation componet & Percentage variation & $F_{\text {st }}$ & $P$-value \\
\hline Among populations & 17 & 1046.79 & 0.78 & 15.10 & 0.151 & $<0.001$ \\
\hline Within populations & 1312 & 5751.70 & 4.38 & 84.90 & & \\
\hline Total & 1329 & 6797.49 & 5.16 & & & \\
\hline
\end{tabular}

$d f$ degree of freedom, SSD sum square differences, $F_{\text {st }}$ genetic differentiation

\section{Table 7}

Genetic identity and genetic distance of populations of Maire yew 


\begin{tabular}{|c|c|c|c|c|c|c|c|c|c|c|c|c|c|c|c|c|c|c|}
\hline Population & Zjla & Zjls & Zjjs & Zjlq & Hnsz & Hnly & Hnxh & Hngy & Jxwy & Jxtg & Jxfy & Jxxf & Fjnp & Fjmx & Fjfz & Fjwp & Gdlc & Gdlz \\
\hline Zjla & & 0.70 & 0.51 & 0.64 & 0.51 & 0.49 & 0.85 & 0.75 & 0.83 & 0.34 & 1.11 & 0.77 & 0.83 & 0.64 & 0.32 & 1.40 & 0.73 & 0.79 \\
\hline Zjls & 0.50 & & 0.80 & 0.29 & 0.35 & 0.69 & 0.89 & 1.00 & 0.54 & 0.77 & 1.21 & 0.81 & 0.83 & 1.01 & 0.95 & 1.21 & 0.57 & 0.99 \\
\hline Zjjs & 0.60 & 0.45 & & 0.77 & 0.61 & 0.25 & 0.67 & 0.67 & 0.78 & 0.62 & 1.34 & 0.86 & 0.58 & 0.68 & 0.61 & 1.18 & 0.85 & 0.89 \\
\hline Zjlq & 0.53 & 0.75 & 0.47 & & 0.31 & 0.62 & 0.87 & 0.91 & 0.56 & 0.64 & 1.08 & 0.71 & 0.82 & 0.88 & 0.79 & 1.15 & 0.53 & 0.84 \\
\hline Hnsz & 0.60 & 0.71 & 0.54 & 0.74 & & 0.46 & 0.83 & 0.74 & 0.45 & 0.61 & 1.04 & 0.72 & 0.66 & 0.77 & 0.66 & 1.21 & 0.48 & 0.97 \\
\hline Hnly & 0.61 & 0.50 & 0.78 & 0.54 & 0.63 & & 0.87 & 0.67 & 0.64 & 0.52 & 1.29 & 0.85 & 0.70 & 0.75 & 0.59 & 1.35 & 0.81 & 1.01 \\
\hline Hnxh & 0.43 & 0.41 & 0.51 & 0.42 & 0.44 & 0.42 & & 0.84 & 0.80 & 0.98 & 1.07 & 0.69 & 0.21 & 0.79 & 1.07 & 1.15 & 0.84 & 0.97 \\
\hline Hngy & 0.47 & 0.37 & 0.51 & 0.41 & 0.48 & 0.51 & 0.43 & & 0.82 & 0.82 & 1.12 & 0.91 & 0.84 & 0.22 & 0.79 & 1.04 & 0.82 & 0.73 \\
\hline Jxwy & 0.44 & 0.58 & 0.46 & 0.57 & 0.64 & 0.53 & 0.45 & 0.44 & & 0.82 & 1.04 & 0.79 & 0.72 & 0.87 & 0.92 & 1.38 & 0.18 & 0.94 \\
\hline Jxtg & 0.71 & 0.46 & 0.54 & 0.53 & 0.54 & 0.60 & 0.38 & 0.44 & 0.44 & & 1.26 & 0.81 & 0.95 & 0.78 & 0.29 & 1.52 & 0.87 & 0.92 \\
\hline Jxfy & 0.33 & 0.30 & 0.26 & 0.34 & 0.35 & 0.28 & 0.34 & 0.33 & 0.35 & 0.29 & & 0.69 & 1.16 & 1.09 & 1.10 & 0.46 & 1.19 & 1.05 \\
\hline Jxxf & 0.46 & 0.45 & 0.42 & 0.49 & 0.49 & 0.43 & 0.50 & 0.41 & 0.45 & 0.45 & 0.50 & & 0.81 & 0.77 & 0.87 & 0.94 & 0.77 & 0.47 \\
\hline Fjnp & 0.44 & 0.44 & 0.56 & 0.44 & 0.52 & 0.50 & 0.81 & 0.43 & 0.49 & 0.39 & 0.31 & 0.45 & & 0.82 & 1.03 & 1.27 & 0.81 & 1.20 \\
\hline Fjmx & 0.53 & 0.36 & 0.50 & 0.42 & 0.46 & 0.47 & 0.45 & 0.80 & 0.42 & 0.46 & 0.34 & 0.46 & 0.44 & & 0.74 & 1.04 & 0.85 & 0.71 \\
\hline Fjfz & 0.73 & 0.39 & 0.55 & 0.46 & 0.52 & 0.56 & 0.35 & 0.46 & 0.40 & 0.75 & 0.33 & 0.42 & 0.36 & 0.48 & & 1.59 & 0.97 & 0.90 \\
\hline Fjwp & 0.25 & 0.30 & 0.31 & 0.32 & 0.30 & 0.26 & 0.32 & 0.35 & 0.25 & 0.22 & 0.63 & 0.39 & 0.28 & 0.35 & 0.20 & & 1.19 & 1.17 \\
\hline Gdlc & 0.48 & 0.57 & 0.43 & 0.59 & 0.62 & 0.44 & 0.43 & 0.44 & 0.83 & 0.42 & 0.30 & 0.46 & 0.45 & 0.43 & 0.38 & 0.31 & & 0.76 \\
\hline Gdlz & 0.45 & 0.37 & 0.41 & 0.43 & 0.38 & 0.36 & 0.38 & 0.48 & 0.39 & 0.40 & 0.35 & 0.63 & 0.30 & 0.49 & 0.41 & 0.31 & 0.47 & \\
\hline
\end{tabular}

${ }^{a}$ The lower left corner is genetic consistency, and the upper right corner is genetic distance.

\section{Figures}




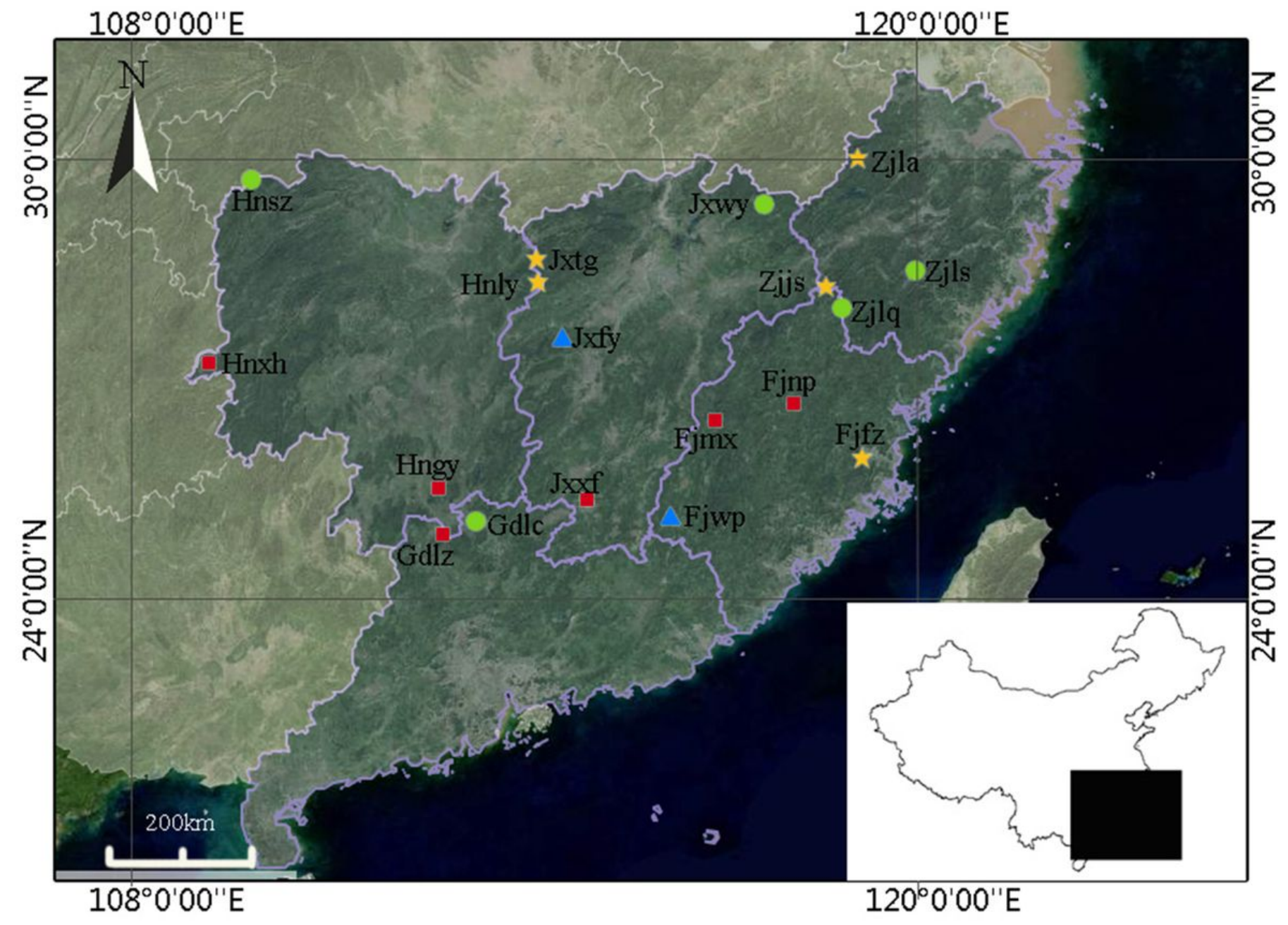

Figure 1

Collecting locations of 18 Maire yew populations(See table 1 for population abbreviations) and their genetic clusters based on UPGMA dendrogram. Yellow star, Cluster A; Green circle, Cluster B; Red square, Cluster C; Blue triangle, Cluster D. (for interpretation of the references to colour in this figure legend,the reader is referred to the web version of this article.) Note: The designations employed and the presentation of the material on this map do not imply the expression of any opinion whatsoever on the part of Research Square concerning the legal status of any country, territory, city or area or of its authorities, or concerning the delimitation of its frontiers or boundaries. This map has been provided by the authors. 


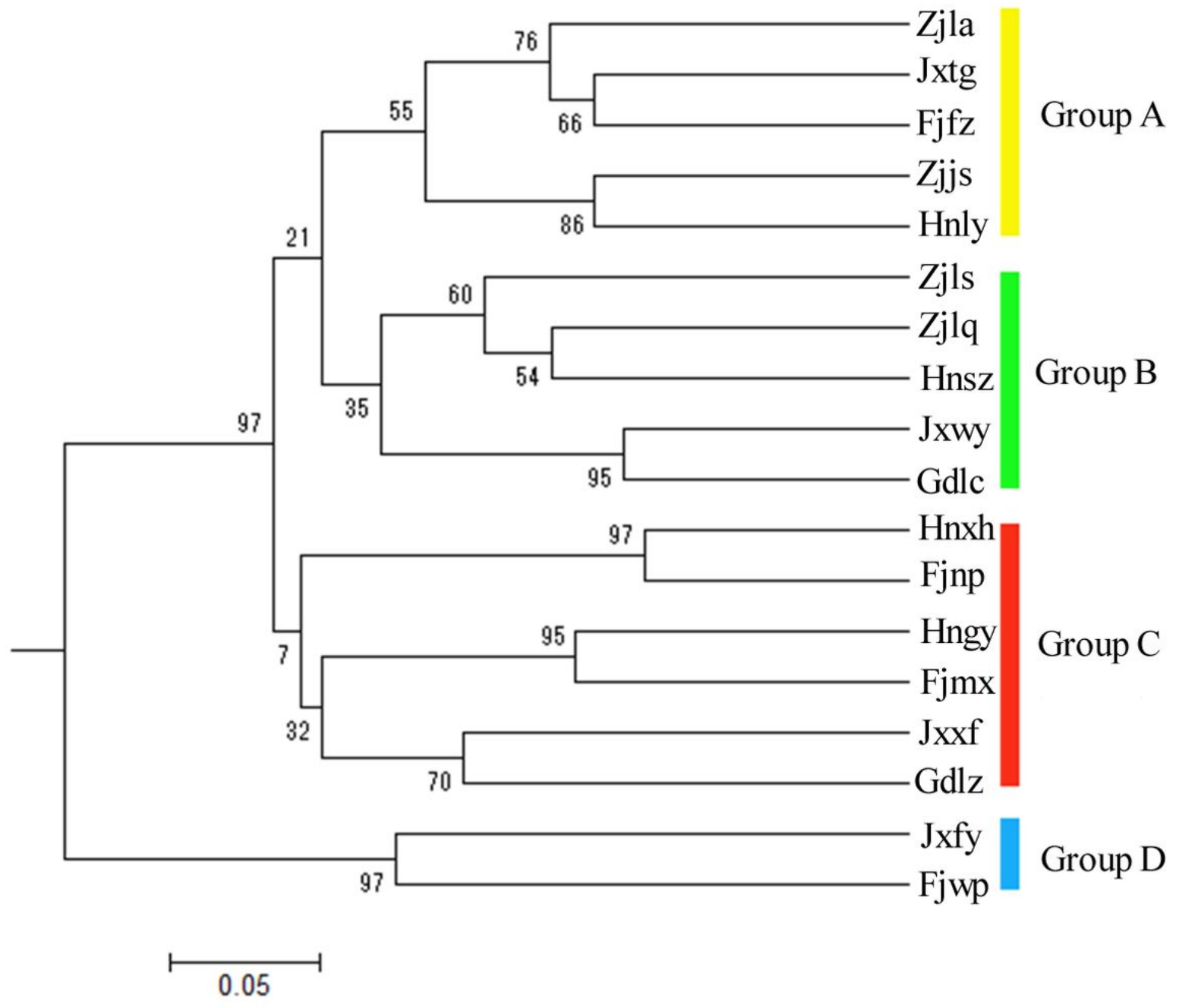

Figure 2

UPGMA dendrograms of Maire yew microsatellite data

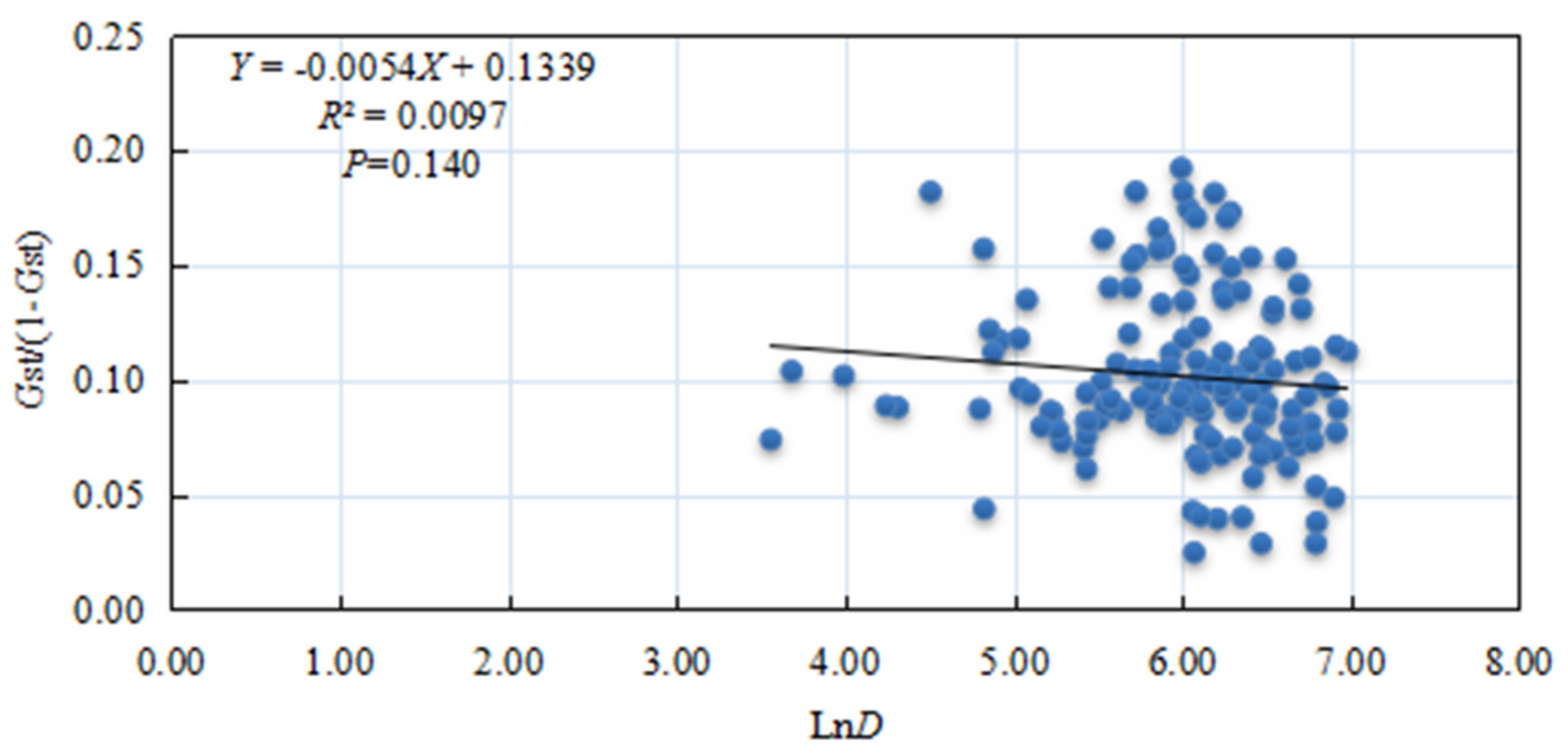


Figure 3

Mantel test between standard genetic distance [Gst/(1-Gst)] and geographical distance (LnD of Maire yew

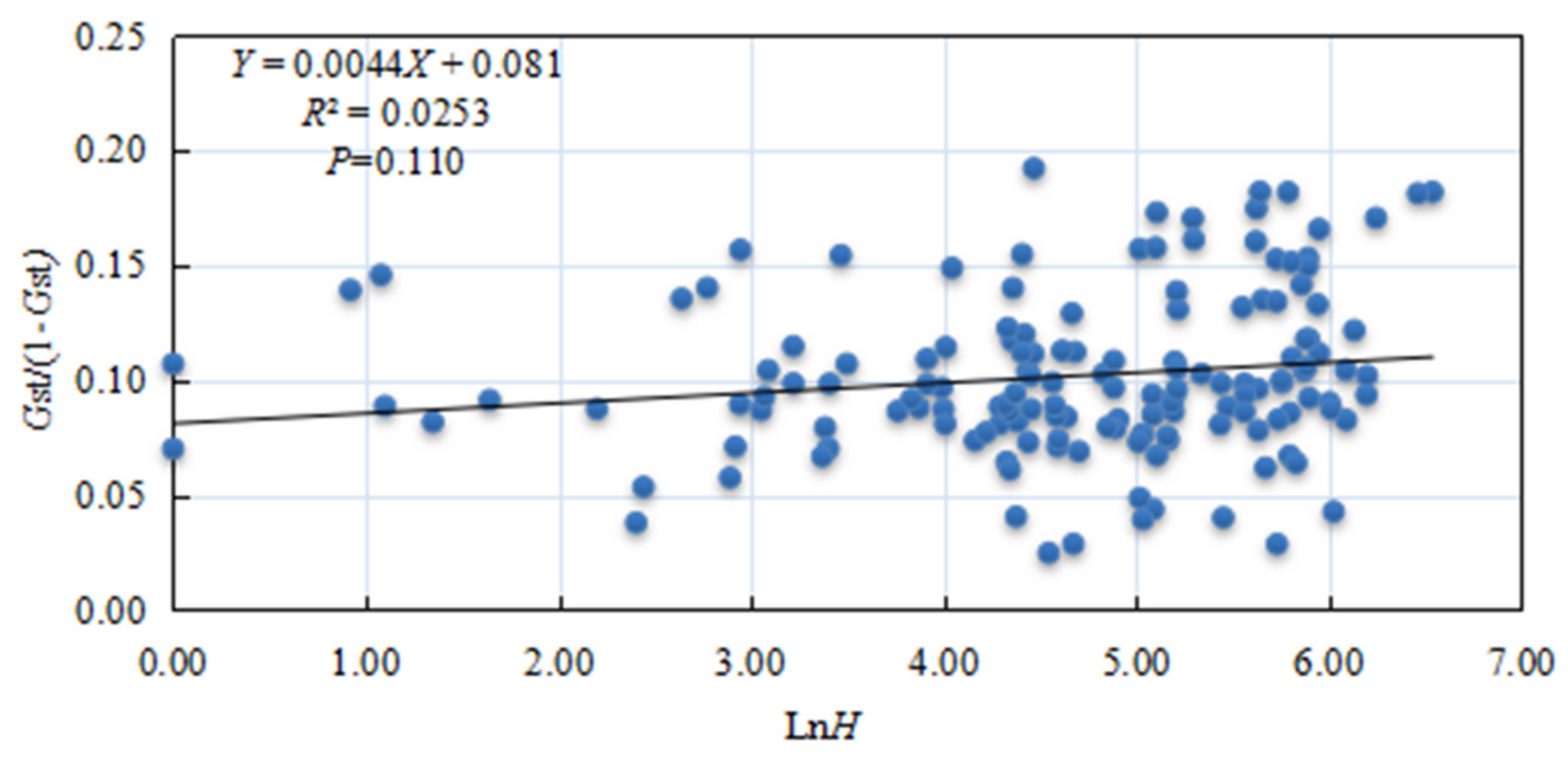

Figure 4

Mantel test between standard genetic distance e $[\mathrm{Gst} /(1-\mathrm{Gst})]$ and altitude difference $(\mathrm{LnH})$ of Maire yew

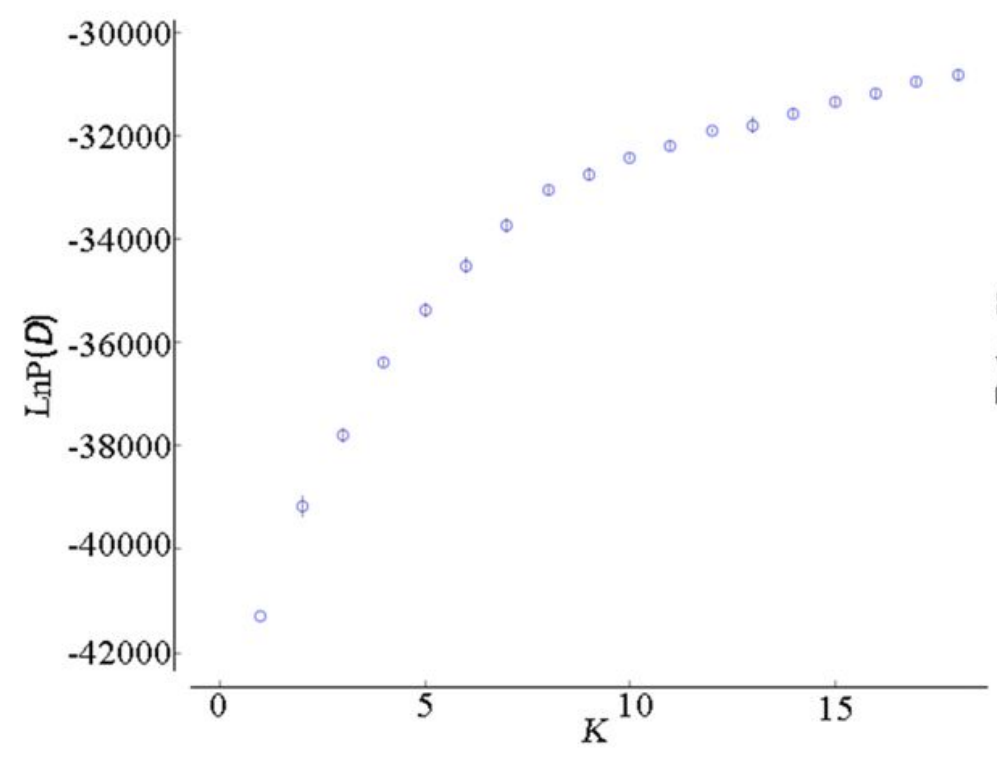

(a)

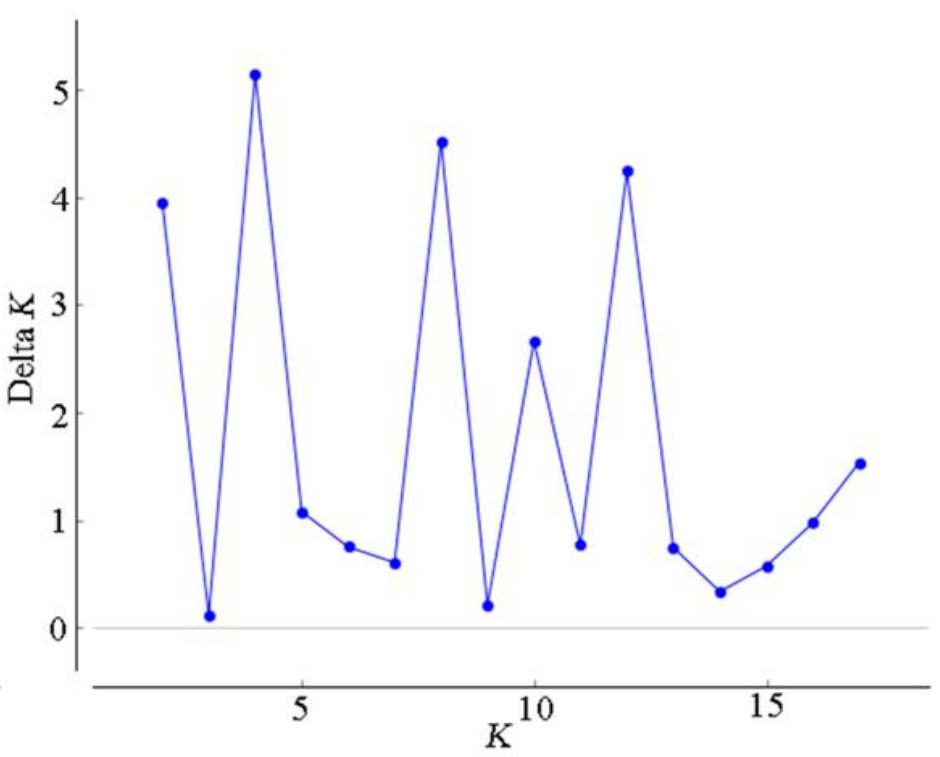

(b)

Figure 5

$\mathrm{LnP}(\mathrm{D})$ and Delta $\mathrm{K}$ value changing with the value of $\mathrm{K}$ 


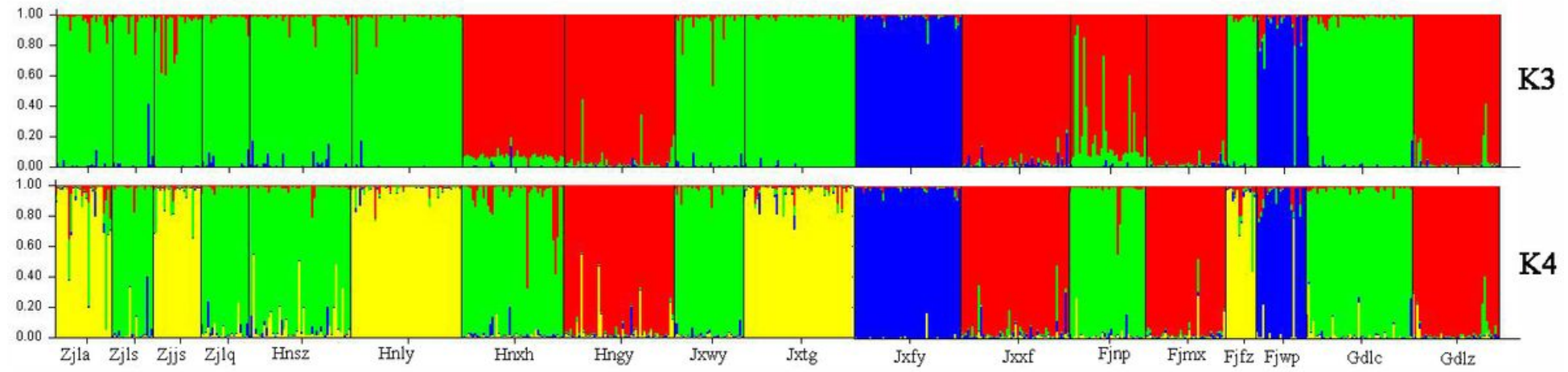

Figure 6

Bayesian cluster analysis of Maire yew microsatellite data from STRUCTURE $(K=3, K=4)$ Note: The ordinate is $Q$ value (the proportion of individuals belonging to different groups in the population). 